\title{
SPASMUS NUTANS
}

\section{Gp Capt TS RAGHURAMAN ${ }^{*}$, Dr (Mrs) NARMADA ${ }^{+}$, Wg Cdr KM SHUKLA ${ }^{\#}$}

\author{
MJAFI $2001 ; 57: 243-244$
}

\section{Introduction}

$\mathbf{S}$ pasmus nutans is a syndrome occurring in early childhood. It consists of a triad of symptoms : head nodding, ocular oscillations and anomalous head position. Ophthalmologic and neurological findings are otherwise normal. This syndrome is benign and has spontaneous resolution [1]. This presentation highlights a case of spasmus nutans with brief review of literature.

\section{Case Report}

Male child aged 4 years 6 months (Fig-1) reported to outpatient clinic with history of rapid eye movements for last three years. As per parents his visual acuity was normal. There were no associated symptoms of gait disturbance or vertigo or hearing deficit. However, parents admitted that his scholastic performance was poor due to illegible handwriting. At the age of 18 months the bos had an episode of typical febrile seizure for which he underwent conservative management. The boy went on to develop head nodding movements and head tilt at the age of 2 years 6 months. Examination of the child indicated that he had normal growth and development. Visual examination revealed constant, bilateral, horizontal and pendular type of nystagmus. There was no effect with change of movement of the eyes. Examination of fundus was normal. Visual acuity was normal for both distant and near vision. Other clinical signs observed were tilt of his head to left and nodding of head intermittently. In neurological examination the only abnormal sign was abnormal handwriting (Fig-2). There were no signs to suggest abnormal cerebellar or vestibular func. tions. IQ assessment was within normal limits.

Based on the triad of symptoms i.e. head nodding, ocular oscillations and anomalous head position and in the absence of other ophthalmologic and neurological findings, a diagnosis of spasmus nutans was made. Computerized tomography of the head ruled out possible accompanying intracranial gliomas. Necessary counselling about the benign nature of the condition was given.

\section{Discussion}

Nystagmus, head nodding, and anomalous head position are symptoms of spasmus nutans. This disorder appears in early childhood and is thought to be self limiting. However, the visual outcome of patients with spasmus nutans is unclear. The resolution of nystagmus has not been proven with quantitative eye movement recordings. 10 patients with spasmus nu- tans were followed up clinically until a mean age of 7 years. Included were quantitative eye and head movement recordings. At their last examination (mean age, 7.1 years), visual acuity in 4 patients was $20 / 20$ in both eyes, in 5 patients it was $20 / 30$ or better in at least one eye, and in 1 patient it was $20 / 50$ in each eye. 3 patients had orthotropia with normal stereo acuity.

The remaining patients had esotropia, dissociated vertical deviation, amblyopia, or latent nystagmus. All patients had fine, intermittent asymmetric, pendular. nystagmus on eye morement recordings. Good visual acuity can be expected in patients with spasmus

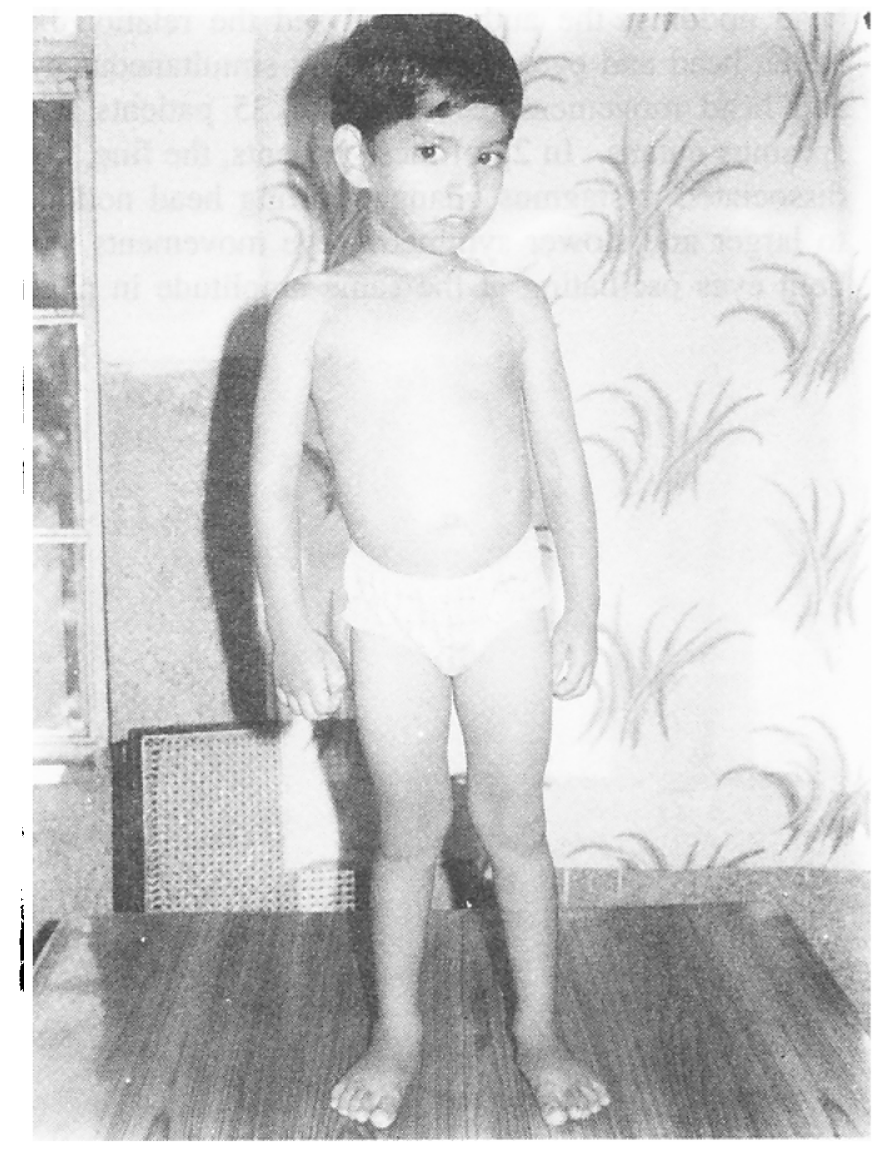

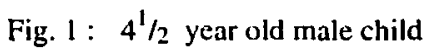

"Senior Advisor (Paediatrics), "Post Graduate Resident (Paediatrics). "Classified Specialist (Paediatrics), Command Hospital (Air Force). Bangalore-560 007. 


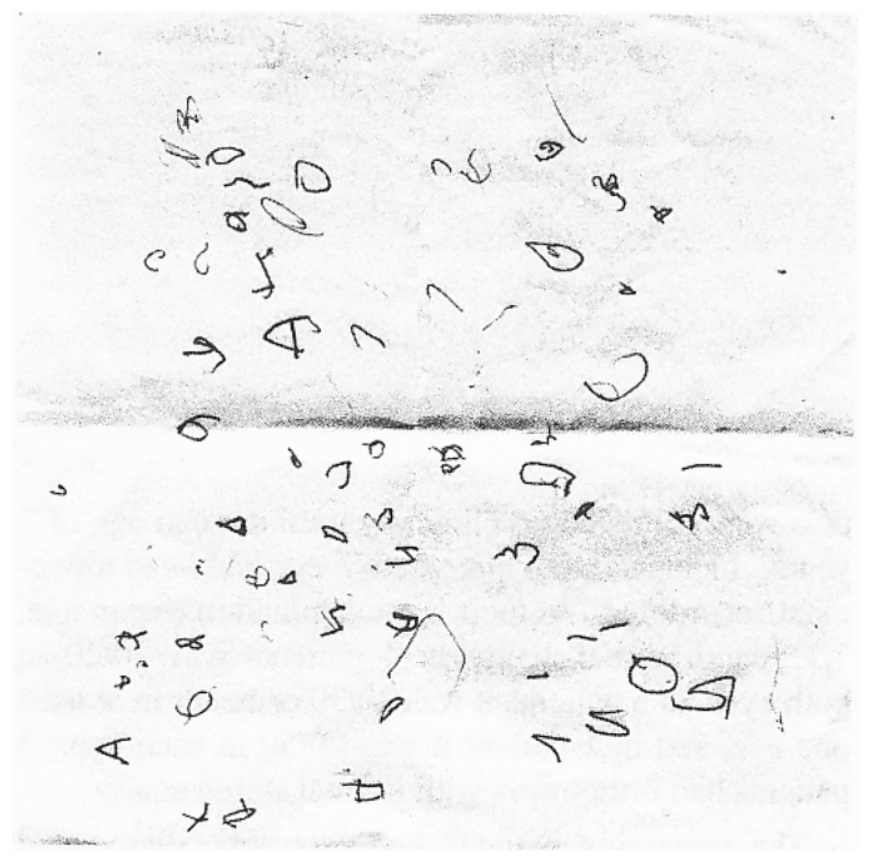

Fig. 2: Handwriting

nutans; one third have normal stereo acuity. However, subclinical nystagmus persists until at least 5 to 12 years of age [2]. To understand the mechanism of head nodding, the authors analysed the relation between head and eye movements by simultaneous eye and head movement recordings of 35 patients with spasmus nutans. In 21 of these patients, the fine, fast, dissociated nystagmus changed during head nodding to larger and slower symmetric eye movements with both eyes oscillating at the same amplitude in phase and 180 degrees out of phase to the head movements, corresponding to a normal compensatory vestibuloocular reflex. These findings indicate that head nodding is compensatory in spasmus nutans [3]. The problem of handwriting could be attributed to the combination of constant nystagmus and head nodding. In another study, the authors conclude that the major etiology for anomalous head posture in these patients is to adopt a gaze null due to congenital nystagmus (62\% of patients) regardless of the direction of their anomalous head posture or type of strabismus. Moving the fixing eye as the first step for the anomalous head posture, combined with moving the nonfixing eye for the resulting strabismus may help treat these patients [4]. This presentation highlights a rare and benign neuro-ophthalmological condition in childhood.

\section{References}

1. Doummar D, Roussat B, Beauvais P, Billette de Villemeur T, Richardet JM. Spasmus nutans : apropos of 16 cases. Arch Pediatr 1998;5:264-8.

2. Gottlob I, Wizov SS, Reinecke RD. Spasmus nutans. A longterm follow-up. Invest Ophthalmol Vis Sci 1995;36:2766-71.

3. Gottlob I, Zubcov AA, Wizov SS, Reinecke RD. Head nodding is compensatory in spasmus nutans. Ophthalmology 1992;99:1024-31.

4. Hertle RW, Zhu X. Oculographic and clinical characterization of 37 children with anomalous head postures, nystagmus, and strabismus : the basis of a clinical algorithm. JAAPOS $2000 ; 4: 25-32$. 